WellBeing International

WBI Studies Repository

$12-1996$

\title{
Sow Preference for Types of Flooring in Farrowing Crates
}

P. A. Phillips

Agriculture and Agri-Food Canada

D. Fraser

Agriculture and Agri-Food Canada, dfraser@mail.ubc.ca

B. K. Thompson

Agriculture and Agri-Food Canada

Follow this and additional works at: https://www.wellbeingintlstudiesrepository.org/houcfani

Part of the Agribusiness Commons, Animal Studies Commons, and the Operations and Supply Chain Management Commons

\section{Recommended Citation}

Phillips, P. A., Fraser, D., \& Thompson, B. K. (1996). Sow preference for types of flooring in farrowing crates. Canadian Journal of Animal Science, 76(4), 485-489.

This material is brought to you for free and open access by WellBeing International. It has been accepted for inclusion by an authorized administrator of the WBI Studies Repository. For more information, please contact wbisr-info@wellbeingintl.org.

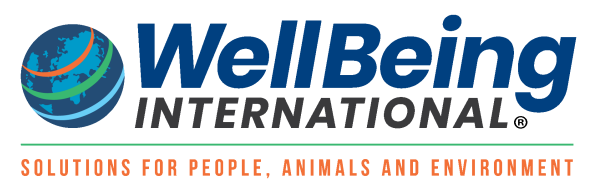




\title{
Sow Preference for Types of Flooring in Farrowing Crates
}

\author{
P.A. Phillips, D. Fraser, and B.K. Thompson \\ Agriculture and Agri-Food Canada
}

\begin{abstract}
KEYWORDS
sow, farrowing crate, flooring, preference testing, animal welfare
\end{abstract}

\section{ABSTRACT}

A preference-testing apparatus was used to provide sows with continuous access to three identical farrowing crates, each with a different type of flooring. The crates radiated from a central hub area sufficiently large for sows to enter or leave any crate freely. In exp. 1, nine sows from a concrete-floored gestation room were offered crates over concrete, plastic-coated rod, and galvanized metal rod. In exp. 2, sows were pre-exposed for a period of 1 wk to one of the three floors before entry into the preference testing apparatus. Video recording was used to determine sow position from $3 \mathrm{~d}$ before to $13 \mathrm{~d}$ after farrowing in exp. 1 and for a 3-d period before and 3-d period after farrowing in exp. 2. In exp. 1, sows showed a strong preference $(P<0.05)$ for the concrete floor before farrowing, but this preference had diminished by the final week.in the apparatus $(P \approx$ 0.16). In exp. 2, sows pre-exposed to metal or plastic-coated flooring made more voluntary use of these products, but the metal floor was strongly avoided during and immediately after farrowing. Overall, concrete seemed to be a preferred floor material for sows at farrowing.

A number of studies have examined the preferences of sows for different aspects of the farrowing environment, including spacial configuration (Hunt and Petchey 1987, 1989; Baxter 1991; Phillips et al. 1991, 1992b) and use of bedding (Hutson and Haskell 1990; Arey et al. 1991). However, for practical pig production in North America, where narrow crates pre-dominate and bedding is not commonly used, the most commonly asked questions about farrowing accommodation are related to the choice of flooring (Quaife 1987; Wilkins 1987; Damman and Bal 1983; Miller 1993).

Choosing an optimal flooring in the farrowing area is complicated for several reasons. First, there are many properties of flooring to consider: surface texture (abrasiveness, traction), durability, ease of cleaning (void:solid ratio), hygiene, risk of injuries to legs and feet, and effects on animal performance (Kornegay and Lindemann 1984). Second, the needs of the sow and her litter are different. Finally, cost, which varies greatly from product to product, is often an overriding consideration. 
Metal floors, such as woven wire or metal slats, have become very popular with producers (see Miller 1993). Four reasons seem to account for this: low cost, high durability, hygiene, and ease of cleaning. While metal products do excel in these operational aspects, there is some evidence that other materials may be better suited to the comfort and behavior of the sow and litter. Christison and deGooijer (1986) studied the effect of various types of farrowing flooring on the sow's foothold. They found that sows required fewer foot movements to get up on concrete compared with perforated metal slats. Edwards and Lighfoot (1986) studied leg and teat damage in sows at farrowing and weaning on several floor types. Their findings indicated more injury with perforated flooring products compared with the solid concrete with limited bedding. Lorenz (1982) found that injury levels in sows from farrowing to weaning were similar for cast iron slats and solid concrete floors but worse with woven wire flooring.

Environmental preference testing, whereby animals choose among two or more different options in the environment, provides useful information for environmental design (Fraser et al. 1993). Some preference testing of flooring products has been done with young pigs (Farmer and Christison 1982), but little is known about sows' preferences for different types of flooring. In this study, a unique preference testing apparatus was used to compare three floor products, each representing one of the three most commonly used floor materials: concrete, metal, and plastic.

\section{MATERIALS AND METHODS}

\section{Test Apparatus}

The test apparatus offered individual sows free access to three identical farrowing crates, each positioned over a sample of a different floor type. The three crates, each $1.5 \mathrm{~m}$ long and $0.6 \mathrm{~m}$ wide, radiated from a central hub area sufficiently large to allow sows to exit from one crate and move freely into another. Each crate was equipped with a feeder forming the front end of the crate. The apparatus was mounted on a platform $300 \mathrm{~mm}$ above the floor and was located in a temperature-controlled room $\left(22-27^{\circ} \mathrm{C}\right)$. Details of the apparatus and its management have been published previously (Phillips et al. 1991, 1992b).

Three samples of flooring, each $0.76 \mathrm{~m}$ wide and $1.85 \mathrm{~m}$ long, were selected to represent materials commonly found in the swine industry. The concrete floor consisted of a solid concrete slab $4 \mathrm{~cm}$ thick with a wood-float finish. The plastic-coated floor consisted of vinyl-coated round metal rods, $1 \mathrm{~cm}$ in diameter in a parallel pattern $2 \mathrm{~cm}$ apart, on center. The metal floor consisted of galvanized steel rods, 1 $\mathrm{cm}$ wide and triangular in cross section, placed in a parallel pattern $2 \mathrm{~cm}$ apart, on center. This product is widely used in the swine industry (see Miller 1993). The metal and plastic materials were oriented with the slots parallel to the long axis of the crate. Rubber mat covered the piglet creep area between the floor samples. To protect against possible position effects in the room, each type of flooring was offered an equal number of times in each segment of the preference testing apparatus.

\section{Experimental Design}

Two experiments were conducted. In exp. 1, nine sows were brought directly from a concrete-floored gestation room to the testing apparatus. Each sow was housed in the apparatus from about $5 \mathrm{~d}$ before farrowing to $14 \mathrm{~d}$ after farrowing.

In exp. 1, the sows' initial floor preferences appeared to weaken after 2 wk in the apparatus, suggesting that the exposure to unfamiliar flooring that occurred in the apparatus may have influenced the sows' preferences. To test this possibility, exp. 2 used 18 sows that were preconditioned to one of the three floor types for 1 wk before testing. The animals were moved from the gestation area about 2 wk before farrowing was due, and housed for $7 \mathrm{~d}$ in a standard farrowing crate floored in one of the three materials. The sows were then moved to the preference testing apparatus about 1 wk before farrowing was due. 


\section{Animals and Procedures}

Yorkshire and Yorkshire $\times$ Landrace sows ranging from 2 nd to 7 th parity were selected as available from our specific pathogen-free herd at Ottawa. Use of the different floor types was monitored by time-lapse video recording by an overhead camera at a rate of 1 frame every 3 min (480 observations $\mathrm{d}^{-1}$ ) for the full time the sows were in the apparatus. Because sows rest about $85 \%$ of the time, the time spent resting on each floor was used to indicate floor preference. In exp. 1, the observations were calculated over four periods: the $72 \mathrm{~h}$ ending at the hour when farrowing began (day -3 to -1 ), two $72-\mathrm{h}$ periods after the start of farrowing (Day 1 to 3, day 4 to 6), and the subsequent $168 \mathrm{~h}$ (day 7 to 13) ending on the 13th day after farrowing. In exp. 2, floor preferences were monitored for two 3-d periods, $72 \mathrm{~h}$ after moving into the apparatus and $72 \mathrm{~h}$ after farrowing began.

Daily activity levels (i.e. percentage of frames when the sows were either standing or sitting) were calculated on a daily basis for exp. 1 from $4 \mathrm{~d}$ before farrowing to $13 \mathrm{~d}$ after farrowing.

Daily feed allowance consisted of $3 \mathrm{~kg} \mathrm{~d}^{-1}$ until after farrowing and a larger amount (equal to the-sow's estimated ad libitum intake) thereafter. This daily allowance was divided equally among the three feeders, to compel sows to move to all areas of the preference testing apparatus each day.

\section{Statistical Analysis}

Non-parametric analyses (Siegel 1956) were used because the results were highly non-normal in distribution. Friedman's analysis of variance of ranks was used for overall comparisons of the three floor types. Two-way comparisons were done using the Wilcoxon matched-pairs signed-ranks test to compare the same animals' responses at different times, and the Mann-Whitney $U$ test to compare different animals.

\section{RESULTS}

In exp. 1, one sow selected the center of the apparatus as the most preferred resting site during three periods, and two other sows did the same for one period each. The results for these five observations (out of a total of 36 observations) were ignored. No sows preferred the center of the apparatus in exp.2.

\section{Experiment 1}

The percentage of time that the sows were active (standing or sitting) followed a distinct pattern, with a sharp increase in activity during the $24 \mathrm{~h}$ before farrowing commenced (day -1 ), followed by low levels of activity soon after farrowing, increasing gradually during the first week of lactation (Fig. 1).

Sows in exp. 1 showed a preference for lying on the concrete during each period, but the degree of preference waned with time (Fig. 2). The difference between floor types was highly significant during the early days ( $P<0.005$ on days -3 to -1 and on days 1 to 3 ) but no longer significant $(P \approx 0.16)$ on days 7 to 13 when the sows' activity levels (standing or sitting) had returned to near prefarrowing levels (Fig. 1). Most of the individual sows showed an overall preference for the concrete in all four periods. There was no evidence of a preference for any of the three crate positions in the room in any of the periods.

The sows' active time was more evenly distributed among the three crates partly because the sows had to enter each crate daily to obtain feed. On average, the sows spent about $3 \%$ of their time active on the concrete, about $2 \%$ on each of the metal and plastic-coated flooring, and $1 \%$ in the central hub area. 
Fig. 1. Percentage of time spent active (mean \pm SEM for nine sows) during the $4 \mathrm{~d}$ before and $13 \mathrm{~d}$ after the beginning of farrowing.

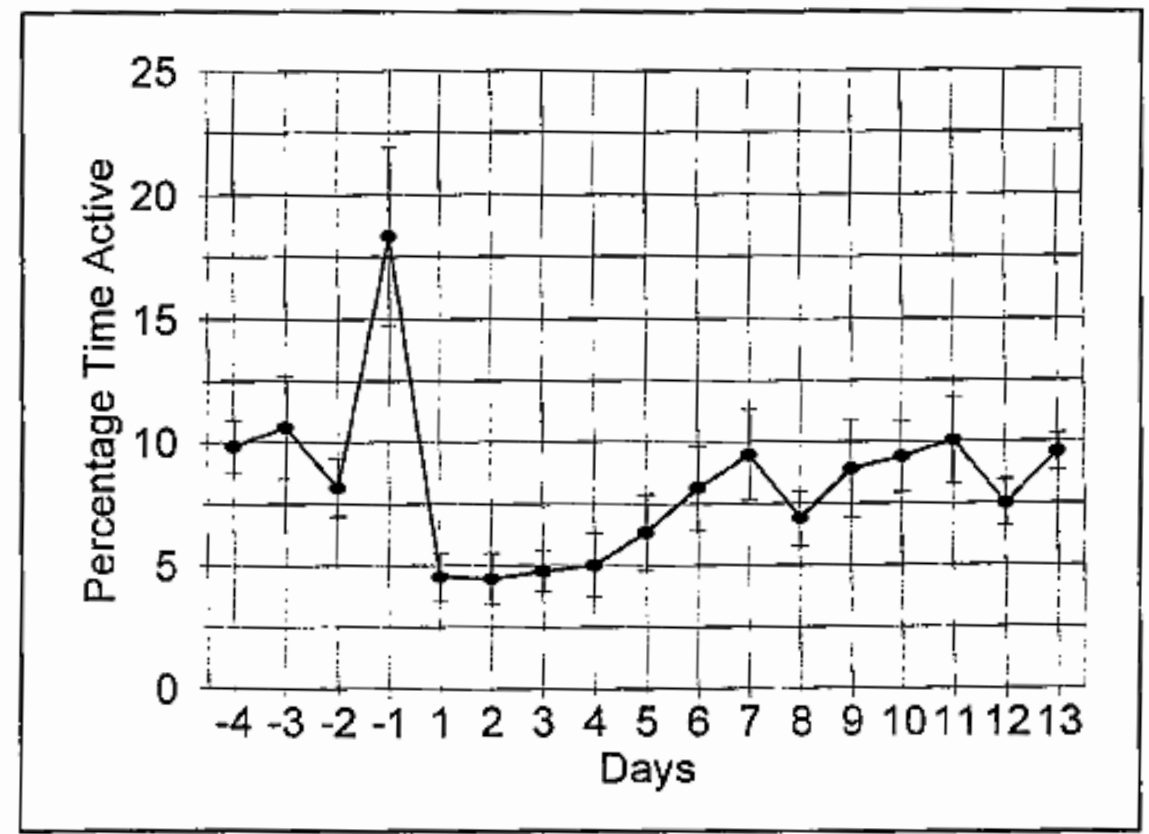

\section{Experiment 2}

As in exp. 1, sows showed significant preferences in both periods studied (Fig. 2; $P<0.01$ by Friedman's analysis of variance of ranks). However, pre-exposure to different flooring materials appeared to influence the preferences (Fig. 3). The six sows pre-exposed to concrete gave results similar to exp. 1, with a strong preference for the concrete floor both before and after farrowing. Five of these six sows selected the concrete floor the majority of the time. Compared to these animals, the six sows pre-exposed to metal showed much greater use of the metal floor before farrowing $(P<0.05$ by the Mann-Whitney $U$ test), with four of these six sows using metal more than the other floor types before farrowing. Sows pre-exposed to plastic-coated flooring did not show much use of the plastic-coated material before farrowing, but they did show less use of concrete $(P<0.05)$ and more use of metal $(P<0.01)$ than the sows pre-exposed to concrete.

From days 1 to 3 (during and after farrowing) sows showed very little use of the metal floor. Of the six sows with an overall preference for metal before farrowing, all switched to either concrete (four cases) or plastic-coated flooring (two cases) on days 1 to 3. In all 18 animals, the use of metal flooring declined significantly $(P<0.02$ by the Wilcoxon test) from the period before farrowing to the period after farrowing. As in exp. 1, there was no evidence of a preference for any of the three crate positions in the room.

\section{DISCUSSION}

In commercial swine production, sows are often moved from a concrete-floored gestation area into a farrowing area with a different floor type. The new flooring may require a period of learning and adaptation before the sows go through their normal postural changes with ease. This may explain why, in exp. 1, the sows rarely lay on the unfamiliar types of flooring when first moved into the apparatus, but 
gradually showed more acceptance of plastic-coated and metal flooring as time passed and their exposure to these materials increased.

Fig, 2. Mean percentage time resting on each of the three test floors in exps. 1 and 2, expressed as a percentage of total resting time, for the time periods shown. The three floors are identified as $C$ (concrete), $P$ (plastic-coated), and $M$ (metal). Results are based on $n=8$ or 7 sows because three of the nine sows preferred the central hub area of the apparatus during certain periods. Numerals show the number of sows choosing that floor type as the overall preference in that interval.

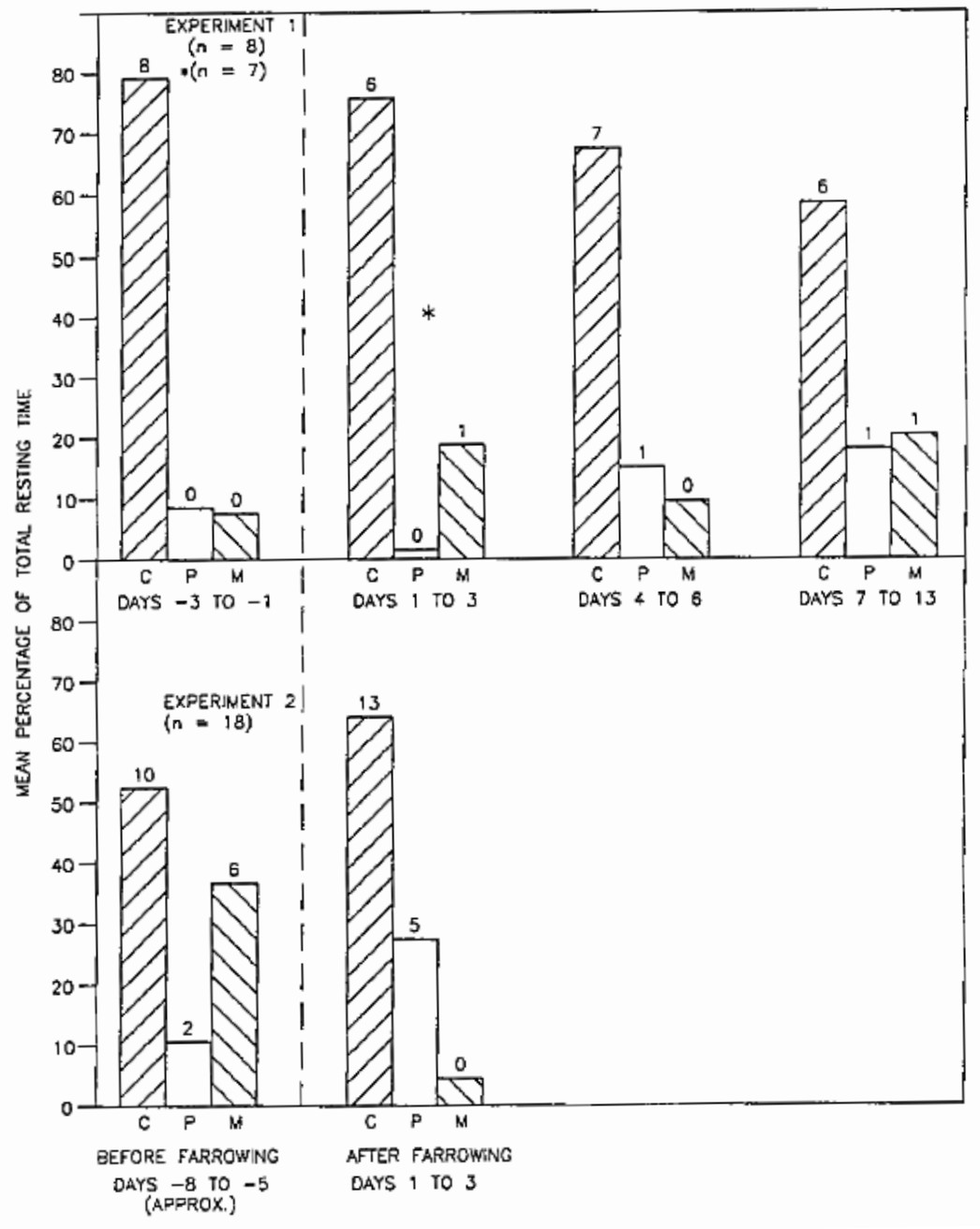

Experiment 2 suggested that 1 wk of exposure to a new flooring product (intended as a rough approximation to the commercial practice of moving sows to the farrowing area during the week before farrowing is due) is effective in creating increased acceptance of an unfamiliar floor type. This result reinforces the wisdom of giving sows time to adjust to the farrowing area before parturition, so that forced use of an unfamiliar floor type does not add to stress at farrowing.

In addition to their initial avoidance of unfamiliar flooring products, the sows showed a general avoidance of the metal flooring during and immediately after farrowing, even in cases where they had preferred the metal floor before farrowing. Sows living under semi-natural conditions spend considerable time selecting 
and preparing a nest site on the day before farrowing (Jensen 1986). Because newborn piglets need a warmer environment than does a grown sow, the sow should ideally choose a particularly warm farrowing area. On the day before farrowing, the udder of the sow becomes enlarged, and the skin temperature of the udder increases noticeably (Fiala and Hurnik 1983), presumably because of the greater blood flow and metabolic activity involved in milk production. Following an hypothesis proposed by Baxter (1982), we suggest that the sow chooses a farrowing site that does not feel cool on her newly warm and distended udder, thereby helping to ensure that the area is suitable for newborn young. This hypothesis is reinforced by the observation that sows often lie with the udder facing a heat source soon after farrowing but not at other times (Titterington and Fraser 1975 Gravås 1979). Given its greater thermal conductance, the metal flooring may have felt cooler and for this reason may have been avoided by the sows at farrowing.

Fig. 3. Mean percentage time resting on each of the three test floors in exp. 2, expressed as a percentage of total resting time, and separated according to the type of flooring to which the animals had been preexposed ( $n=6$ in each chart). The three floors are identified as C (concrete), P (plastic-coated), and M (metal). Numerals show the number of sows choosing that floor type as the overall preference in that interval.

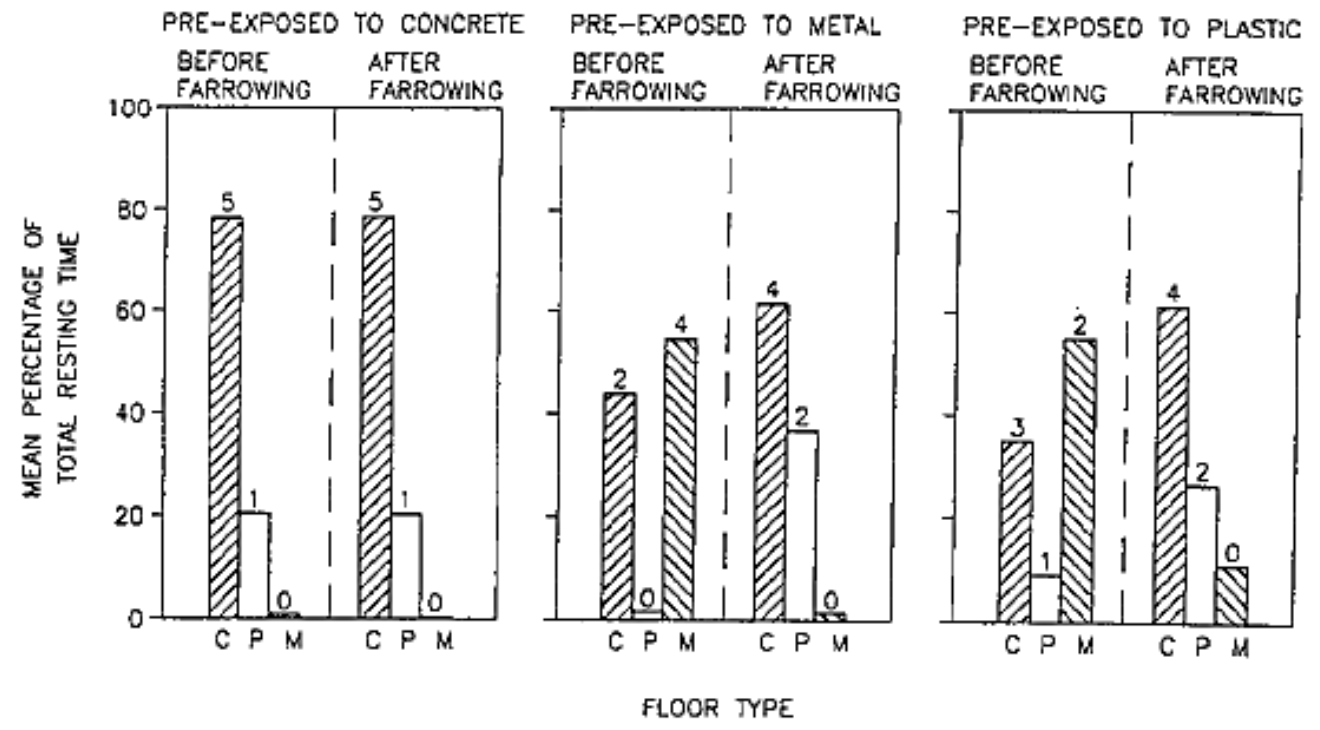

Despite the general trend away from concrete flooring for farrowing sows in commercial practice, these experiments showed that concrete was well accepted by the sows, even after a week of exposure to alternative flooring products. Concrete floors present several problems, including abrasions to the piglets' legs and teats (Phillips et al. 1992a, 1995), and some difficulties in warmth, cleanliness, and disinfection. However, the present experiments, together with the work of Christison and deGooijer (1986), indicate that concrete is well accepted and offers good foothold, as well as being durable and low in cost. A compromise worth considering would be a concrete slab located directly beneath the sow, with a better insulated and less abrasive surface to either side for the piglets. However, problems of cleaning and disinfection of concrete would have to be overcome.

\section{ACKNOWLEDGMENTS}

The authors wish to thank J. M. Leclerc, B. Pawluczuk, S. Leffler, and R. Pella for their valuable assistance. 


\section{REFERENCES}

Arey, D. S., Petchey, A. M. and Fowler, V. R. 1991. The pre-parturient behaviour of sows in enriched pens and the effect of preformed nests. Appl. Anim. Behav. Sci. 31: 61-68.

Baxter, M. R. 1982. The nesting behaviour of sows and its disturbance by confinement at farrowing. Pages 101-114 in W. Bessei, ed. Disturbed behaviour of farm animals. Eugen Ulmer, Stuttgart. Germany.

Baxter, M. R. 1991. The 'freedom' farrowing system. Fm. Bldg. Prog.104: 9-15.

Christison, G. I. and deGooijer, J. A. 1986. Foothold of sows on farrowing crate floors. Livest. Prod. Sci. 15: 191-200.

Damman, H. and Bal, A. 1985. What's the best floor in the farrowing house? Pigs - Misset 1: 20-23.

Edwards, S. A. and Lightfoot, A. L. 1986. The effect of floor type in farrowing pens on pig injury. II. Leg and teat damage of sows. Br. Yet. J.142: 441-445.

Farmer, C. and Christison, G. I. 1982. Selection of perforated floors by newborn and weanling pigs. Can. J. Anim. Sci. 62: 1229-1236.

Fiala, S. and Hurnik, J. F. 1983. Infrared scanning of cattle and swine. Can. J. Anim. Sci.63: 1008 (Abstr.).

Fraser, D., Phillips, P. A. and Thompson, B. K. 1993. Environmental preference testing to assess the wellbeing of animals -- an evolving paradigm. J. Agric. Environ. Ethics 6 (Suppl. 2): 104-114.

Gravås, L. 1979. Behavioural and physical effects of flooring on piglets and sows. Appl. Anim. Ethol. 5: 333-345.

Hunt, K. and Petchey, A. M. 1987. A study of environmental preferences of sows around farrowing. Fm. Bldg. Prog. 89: 11-14.

Hunt, K. and Petchey, A. M. 1989. Degree of enclosure preferred by sows around farrowing. Anim. Prod. 48: 643. (Abstr.)

Hutson, G. D. and Haskell, M. J. 1990. The behaviour of farrowing sows with free and operant access to an earth floor. Appl. Anim. Behav. Sci. 26: 363-372.

Jensen, P. 1986. Observations on the maternal behaviour of free-ranging domestic pigs. Appl. Anim. Behav. Sci. 16: 131-142.

Kornegay, E. T. and Lindemann, M. D. 1984. Floor surfaces and flooring materials for pigs. Pig News and Info. 5: 351-357.

Lorenz. J. 1982. Cast-iron slats vs wire. Pig American July: pp. 12-13.

Miller, M. 1993. A shopper's guide to farrowing house flooring. Pork '93 No. 12: 18-22.

Phillips, P. A., Fraser, D. and Thompson, B. K. 1991. Preference by sows for a partially enclosed farrowing crate. Appl. Anim. Behav. Sci.32: 35-43. 
Phillips, P. A., Fraser, D. and Buckley, D. J.1992a. Simulation tests on the effect of floor temperature on leg abrasions in piglets. Trans. ASAE 35: 999-1003.

Phillips, P. A., Fraser, D. and Thompson, B. K. 1992b. Sow preference for farrowing crate width, Can. J. Anim. Sci. 72: 745-740.

Phillips, P. A., Fraser, D. and Pawluczuk, B. 1995. Effects of cushioned flooring on piglet leg injuries. Trans. ASAE 38: 213-216.

Quaife, T. 1987. Farrowing floors: no one can agree which is best. Pork '87 No.7: 55-58.

Siegel, S. 1956. Nonparametric statistics for the behavioral sciences. McGraw-Hill Book. Co., New York, NY.

Tiitterington, R. W. and Fraser, D. 1975. The lying behaviour of sows and piglets during early lactation in relation to the position of the creep heater. Appl. Anim. Ethol. 2: 47-53.

Wilkins, D. 1987. What's the best crate floor? Country Guide 106(7): H20-H23. 